\title{
Peritumoral brain edema in intracranial meningiomas: the emergence of vascular endothelial growth factor-directed therapy
}

\author{
Jack Hou, M.D., ${ }^{1,2}$ Varun R. Kshettry, M.D., ${ }^{2}$ Warren R. Selman, M.D., ${ }^{1}$ \\ and Nicholas C. Bambakidis, M.D. ${ }^{1}$ \\ ${ }^{1}$ Department of Neurological Surgery, University Hospitals Case Medical Center; and ${ }^{2}$ Department of \\ Neurological Surgery, Cleveland Clinic, Cleveland, Ohio
}

\begin{abstract}
Meningioma is the second most common type of adult intracranial neoplasm. A substantial subset of patients present with peritumoral brain edema (PTBE), which can cause significant morbidity via mass effect, complicate surgical management, and impact the safety of stereotactic radiosurgery. Recent studies suggest a close relationship between vascular endothelial growth factor-A (VEGF-A) expression and PTBE development in meningiomas. The authors performed a systematic review of the literature on the pathogenesis of PTBE in meningiomas, the effectiveness of steroid therapy, the role played by VEGF-A, and the current clinical evidence for antiangiogenic therapy to treat peritumoral brain edema. Mounting evidence suggests VEGF-A is secreted directly by meningioma cells to induce angiogenesis and edemagenesis of tumoral as well as peritumoral brain tissue. The VEGF-A cascade results in recruitment of cerebral-pial vessels and disruption of the tumor-brain barrier, which appear to be requisite for VEGF-A to have an edemagenic effect. Results of preliminary clinical studies suggest VEGF-directed therapy has modest activity against recurrent and progressive meningioma growth but can alleviate PTBE in some patients. A comprehensive understanding of the VEGF-A pathway and its modulators may hold the key to an effective therapeutic approach to treating PTBE associated with meningiomas. Further clinical trials with larger patient cohorts and longer follow-up periods are warranted to confirm the efficacy of VEGF-directed therapy.
\end{abstract}

(http://thejns.org/doi/abs/10.3171/2013.8.FOCUS13301)

$\begin{array}{llccc}\text { KEY WORDS } & \bullet \quad \text { meningioma } & \text { brain edema } & \bullet & \text { angiogenesis } \\ \text { vascular endothelial growth factor } & \bullet & \text { steroid }\end{array}$

$\mathrm{M}$ ENINGIOMAS originate from arachnoid cap cells and are the second most common type of intracranial adult neoplasm, accounting for $20 \%$ of all intracranial tumors..$^{7,66,96}$ According to the Central Brain Tumor Registry of the US, the annual incidence of meningiomas is 7.22 per 100,000 and increases with age even beyond 85 years without reaching a peak. ${ }^{22}$ Intracranial meningiomas outnumber spinal meningiomas by 10 -fold and $85 \%$ occur supratentorially. ${ }^{73}$ Females are twice as likely to be affected. However, higher-grade meningiomas occur more often in men. ${ }^{53}$

The WHO classifies meningiomas into 9 low-grade (Grade I) subtypes and 3 subtypes each in Grade II and Grade III, which constitute 80\%, 15\%-20\%, and 1\%-3\%

\footnotetext{
Abbreviations used in this paper: ICP = intracranial pressure; NRP1-R = neuropilin-1 receptor; PFS = progression-free survival; PTBE = peritumoral brain edema; $\mathrm{RT}-\mathrm{PCR}=$ reverse transcription polymerase chain reaction; VEGF = vascular endothelial growth factor; VEGFR = VEGF receptor.
}

of cases, respectively. The most common subtypes are meningotheliomatous $(63 \%)$, transitional or mixed type (19\%), and fibrous (13\%) meningiomas. ${ }^{71}$ Thus, most meningiomas are benign tumors with a 5-year recurrence rate of only $5 \%$ following gross-total resection. ${ }^{71}$

Although 97\%-99\% of meningiomas are slow-growing Grade I and II tumors, they can cause significant morbidity via edema production that exerts mass effect on neighboring structures. Indeed, 38\%-67\% of patients with intracranial meningioma present with a variable amount of peritumoral brain edema (PTBE), ${ }^{30}$ which causes elevated intracranial pressure (ICP) and is associated with a shorter time to diagnosis and an increased likelihood of developing symptoms. ${ }^{5,21,90}$ Severe PTBE contributes significantly to the development of pre- and postoperative seizures. ${ }^{48,92}$ Peritumoral brain edema is often associated with pial blood supply to the meningioma and loss of a clean arachnoid dissection plane at the meningioma/brain interface. ${ }^{1,5}$ Consequently, meningiomas with PTBE are associated with a higher risk of postop- 


\section{J. Hou et al.}

erative intracranial hematoma, intracranial hypertension, receiving blood transfusion, and subsequently a longer hospital stay. ${ }^{1,92}$ As was reported by Sindou and Alaywan, meningiomas with PTBE, particularly located in eloquent areas, present a greater risk for postoperative neurological deficits. ${ }^{80}$ Lastly, PTBE may impact the safety of stereotactic radiosurgery as well. ${ }^{41}$

Therefore, the ability to predict and alleviate PTBE in the management of meningiomas is paramount to improving patient outcomes. To date, several molecules, including vascular endothelial growth factor-A (VEGF-A), have been implicated in the development of PTBE. Disruption of the tumor-brain barrier as a result of tumor penetration of the arachnoid membrane may induce PTBE by introducing edemagenic substances into the brain parenchyma. ${ }^{38,76,87}$ In this review, we describe the current understanding of the pathophysiology underlying PTBE development in intracranial meningiomas and the basic science and clinical literature behind VEGFdirected therapy for treatment of PTBE.

\section{Literature Search}

A MEDLINE search via the PubMed interface was performed for all articles using the key words: "edema," "meningioma," "VEGF," or "vascular endothelial growth factor." Search result abstracts were reviewed for pertinent articles including reviews, laboratory investigations, and clinical series. Reference sections of reviewed articles were searched for additional articles not identified by the original MEDLINE search. Clinical laboratory studies investigating the correlation between VEGF expression and edema development were filtered by adding the supplementary key words "correlation" or "association." Thirteen articles were identified that matched the eligibility criteria.

Articles relating to clinical VEGF-directed therapy in meningiomas were identified by adding the key words "therapy," "treatment," "clinical trial," or "outcome." We identified a total of 3 case reports and 3 case series. Five completed or ongoing clinical trials on VEGF-directed therapy in meningiomas were identified on the website www.clinicaltrials.gov using the key words "meningioma" and "VEGF" or "vascular endothelial growth factor."

\section{Theories on the Pathogenesis of PTBE in Meningiomas}

Previous studies have attempted to correlate PTBE with a number of clinicopathological factors, such as age, sex, location of tumor, tumor size,,$^{11,14,15,29,40,49}$ histological subtypes, ${ }^{29,30,40,49}$ vascularity, ${ }^{12}$ secretory activity, ${ }^{61}$ venous outflow obstruction, ${ }^{14}$ and expression of sex hormones and receptors. ${ }^{9,15,23}$ However, the results have been contradictory, and no clear etiology has emerged from these factors. Nevertheless, 4 theories have been proposed to explain PTBE development.

The secretory-excretory phenomenon states that meningiomas of different histological types produce eosinophilic and periodic acid-Schiff-positive inclusions that are secreted as perivascular proteinaceous substances, ${ }^{2,83}$ which may induce edema formation in neighboring brain tissue directly through osmotic force or via an undetermined secondary mechanism. ${ }^{14}$ Secretory meningiomas in particular had been reported in multiple large series to be associated with severe PTBE exceeding tumor size in $35 \%-41 \%$ of patients and can involve the entire hemisphere. ${ }^{70,93}$ However, they account for only $1.1 \%-3.0 \%$ of all meningiomas ${ }^{18,67,70,89}$ and do not explain PTBE formation in the vast majority of cases. Beyond secretory meningiomas, no association between histological subtypes and the incidence or degree of PTBE has been found in a number of studies. ${ }^{29,49,52,60}$

The cerebral compressive theory postulates that tumor size may play an important role. Larger tumors cause more severe brain compression leading to ischemia and subsequent cytotoxic edema. ${ }^{29,30,52}$ This theory would suggest that the incidence of PTBE should be less in elderly patients, who have some degree of brain atrophy to buffer an intracranial space-occupying mass. However, even very small meningiomas with benign histology may sometimes have extensive PTBE. ${ }^{40}$ In recent series, using an edema index to measure PTBE relative to tumor size, no significant correlation was found with tumor volume or patient age. ${ }^{40,45,52,60}$ Therefore, the compressive effect on the brain alone may not be a major factor in PTBE development.

The vascular compression theory dictates that PTBE is higher in patients with meningiomas occluding major cerebral veins or dural sinuses. However, in the largest angiographic series to date by Bitzer and colleagues (n = 136), lesions involving the cortical and bridging veins and dural sinuses did not show higher PTBE incidence. ${ }^{11}$ There is no doubt that for a small subgroup of meningiomas with involvement of major dural sinuses, obstruction of venous outflow may directly exacerbate preexisting PTBE, ${ }^{36}$ but in the majority of meningiomas, compression of adjacent cortical veins may not be a major culprit for meningioma-related PTBE.

The hydrodynamic theory states that PTBE occurs in the presence of intratumoral congestion. One superselective angiographic analysis $(n=25)$ found hypoplasia of efferent draining veins from the meningioma itself to be associated with a significantly higher edema index ( $p$ $<0.001) .{ }^{88}$ Thus, a growing meningioma secretes angiogenic factors when its blood supply becomes inadequate. Highly permeable immature vessels form and result in leakage of plasma proteins. Tumor swelling in an encapsulated space compresses its venous drainage, resulting in a further increase in intratumoral pressure, intratumoral congestion, and accumulation of angiogenic factors. Consequently, supratentorial meningiomas with PTBE were found to have a $2 \%$ significantly higher intratumoral water content than that derived from control brain tissue from temporal lobectomies. ${ }^{55}$ In the presence of a tumorbrain communication, ${ }^{38}$ fluid and angiogenic factors from the tumor could enter surrounding brain tissue, leading to further angiogenesis in the peritumoral brain. ${ }^{20}$ Vasogenic substances increase the permeability of cerebral-pial capillaries and expansion of PTBE through vasogenic edema (Fig. 1). A range of angiogenic factors has been associated with growth and neovascularization of meningiomas, including VEGF-A, endothelin-1, and caveolin-1.7 Among 


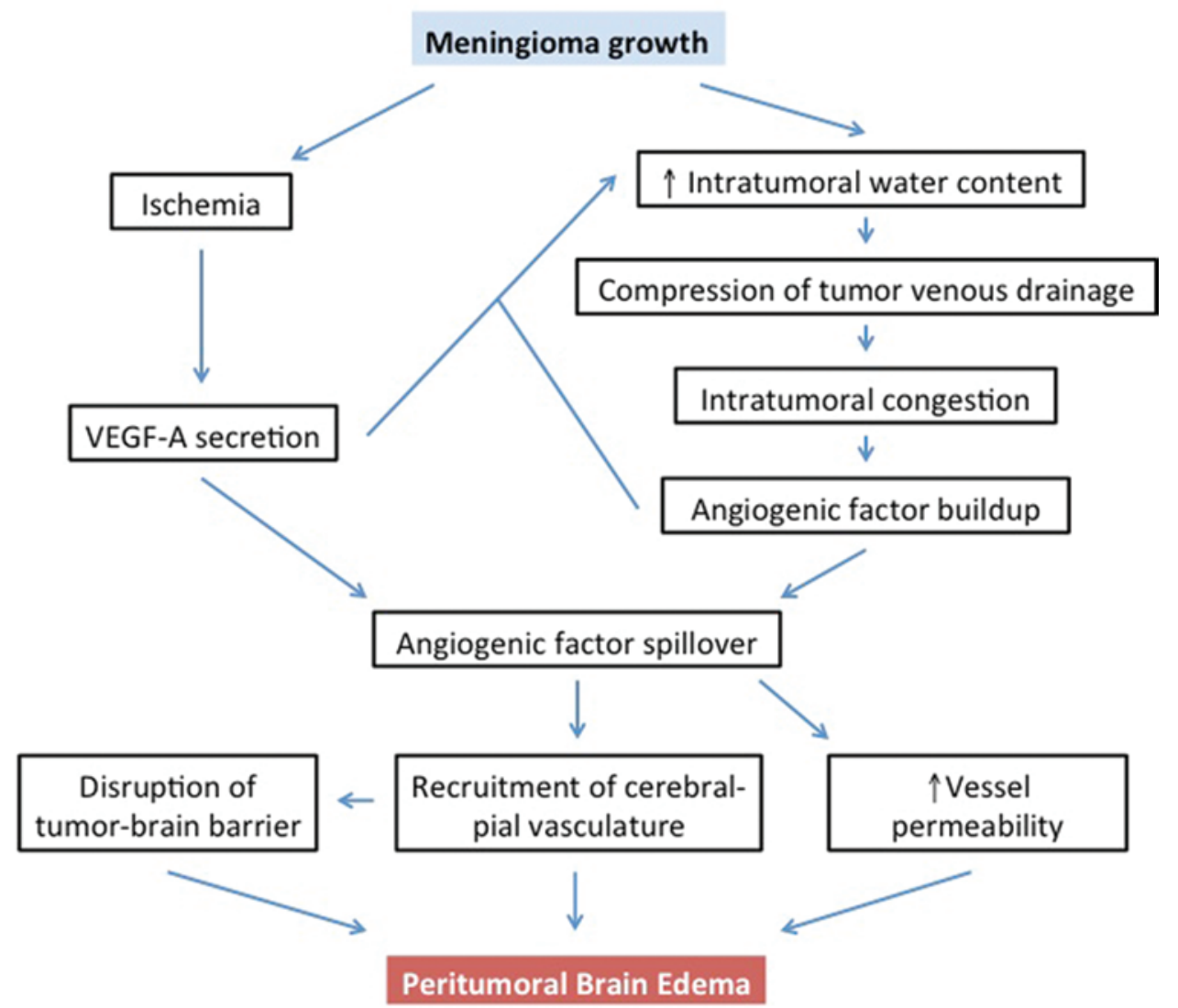

FIG. 1. Proposed mechanisms of PTBE development in intracranial meningiomas.

these factors, VEGF-A is considered to be a major factor in inducing meningioma angiogenesis and edemagenesis and is most consistently associated with PTBE formation in clinical and ex vivo studies. ${ }^{77,97}$ Consequently, VEGF-A may be a core element and a unifying component of the various theories presented above, asserting the multifactorial origin of edemagenesis.

\section{Ineffectiveness of Steroid Therapy}

Steroid therapy has been used in neurosurgery for more than 5 decades to reduce PTBE and thereby lessen symptoms and complications during craniotomy. ${ }^{27,28}$ Even though it is well established for patients harboring malignant intracerebral neoplasms, the effect of steroid therapy on PTBE associated with meningioma has yet to be demonstrated. ${ }^{74}$

Few reports have investigated the level of ICP during such treatment. Skjoeth and Bjerre enrolled 5 patients with meningioma and 8 with glioblastoma or intracerebral metastases, all with a substantial amount of PTBE. ${ }^{82}$ Methylprednisolone $1.4 \mathrm{mg} / \mathrm{kg} /$ day was given over 5 days, and ICP was measured with an intraparenchymal monitor on the contralateral hemisphere of the tumor after patients were supine for 30 minutes. On Day 5, significant clinical improvement and diminished ICP was found in patients with malignant lesions but not in benign or atypical meningiomas. On the contrary, methylprednisolone treatment led to a substantial rise in ICP in all patients with meningioma. These results were supported by those in the study of Andersen and colleagues, who used MR relaxation time imaging to measure PTBE resorption rate following dexamethasone treatment in 23 patients (13 with metastases, 10 with meningiomas) over 7 days. In metastatic tumors, a decrease of edema area and mean T1 relaxation time by $10.3 \%$ and $13.5 \%$, respectively, was observed after 7 days, whereas meningiomas showed no change. ${ }^{3}$ Bodsch and colleagues $(n=60)$ found no change in the water content of biopsied meningioma tissue with increasing intratumoral dexamethasone concentrations, as opposed to malignant lesions in which there was a direct dose-response relationship. ${ }^{13}$ Later studies also demonstrated poor response to corticosteroid therapy in

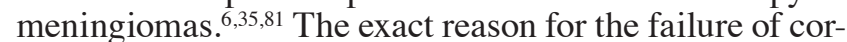
ticosteroid therapy to improve meningioma-associated PTBE is unclear.

The intense enhancement of meningiomas noted on contrasted CT or MRI is mediated by leakage of contrast material through highly permeable vessels of the tumor. The level of contrast enhancement in meningiomas is directly correlated with capillary transendothelial diffusion as expressed by a blood-to-tissue transport rate measured with MRI and a Gd-based volume distribution indicator. ${ }^{4}$ The proposed rationale for using corticosteroids for meningioma-associated PTBE is that they can reduce vessel permeability, resulting in a net reduction in edema fluid production. ${ }^{3,33,81}$ Theoretically, edema reabsorption would then exceed production with resulting attenuation in PTBE. ${ }^{3}$ 


\section{J. Hou et al.}

Bodsch and colleagues found that the content of water and extravasated proteins in meningiomas are almost as high as in glioblastomas and metastases with a significantly smaller fraction of albumin, a relatively small plasma protein. ${ }^{13}$ An alternative hypothesis for the poor response to corticosteroids could be that the vessels of meningiomas exhibit larger fenestrations because meningiomas, in contrast to primary brain tumors, are of mesenchymal origin and therefore have no intrinsic tight blood-tumor barrier as would be expected to a certain degree for neuroepithelial tumors. ${ }^{37,91}$ Corticosteroids might be ineffective in obliterating larger fenestrations observed in meningiomas in comparison with glial tumor vessels, which exhibit a closed endothelial lining. Furthermore, the degree to which a tumor responds to corticosteroids also depends on the number of intracellular corticosteroid receptors. ${ }^{99}$ Consequently, tumors such as metastases that respond favorably to corticosteroids have higher levels of corticosteroid receptors compared with tumors such as meningiomas, which respond poorly and are depleted of corticosteroid receptors. ${ }^{13,98}$

\section{Overview of VEGF}

More than 2 decades of intense investigation has provided evidence that the VEGF pathway represents a critical rate-limiting step in physiological and pathological angiogenesis, such as that associated with tumor growth. ${ }^{25}$ Vascular endothelial growth factor-A is an important member of a family of signaling molecules including VEGF-B, VEGF-C, and VEGF-D, expressed by a number of cells, such as meningioma stromal and endothelial cells in the presence of hypoxia. ${ }^{20}$ Vascular endothelial growth factor-A is well documented to have the ability to induce growth of arterial endothelial cells, thereby promoting a powerful angiogenic response in vivo. ${ }^{46}$ It was originally referred to as vascular permeability factor for its ability to facilitate leakage of plasma proteins with 1000 times the potency of histamine,${ }^{79}$ by inducing endothelial fenestrations $^{72}$ and vasodilation from endothelial cell-derived nitric oxide. ${ }^{43}$ Leakage of plasma proteins extracts water into the interstitial compartment and forms a provisional extracellular gel-like matrix that promotes the development of new blood vessels. Consequently, VEGF-A upregulation, induced by ischemia as meningiomas outgrow their blood supply, was proposed to act as a critical factor in the development of PTBE. ${ }^{24}$

Vascular endothelial growth factor-A interacts with two tyrosine kinase receptors: VEGFR-1 and VEGFR-2. The angiogenic and permeability-enhancing effects of VEGF-A are largely mediated by VEGFR-2. ${ }^{47}$ However, in a membrane-bound or soluble form, VEGFR-1 is proposed to be a "decoy" to negatively modulate VEGF-A activity on the vascular endothelial cells by inhibiting the binding of VEGF-A to VEGFR-2. ${ }^{16}$

Among modulators of VEGFR-2, neuropilin-1 receptor (NRP1-R) is of particular importance. As with VEGF-A, NRP1-R expression is upregulated in ischemia. ${ }^{85}$ Its ligand includes semaphorin-3A. ${ }^{51}$ When coexpressed in cells with VEGFR-2 in the absence of semaphorin-3A, NRP1-R acts as a coreceptor to enhance the binding of VEGF-A to VEGFR-2 in a manner that augments the effectiveness of VEGFR-2-mediated signal transduction. ${ }^{84}$ However, in the presence of semaphorin$3 \mathrm{~A}$ when bound to NRP-1R, the VEGF-A-mediated angiogenic effect is attenuated. ${ }^{54}$ Furthermore, semaphorin$3 \mathrm{~A}$ in high concentrations repels endothelial cells and induces their apoptosis. ${ }^{34}$ Thus, the ratio of VEGF-A to semaphorin-3A was postulated to regulate angiogenesis rather than VEGF-A alone, and may have prognostic and therapeutic implications in meningiomas. ${ }^{7,8}$

\section{Correlation Between VEGF-A Level and PTBE}

Despite marked variation in VEGF detection/quantification methods over the past 15 years, the vast majority of data support a close relationship between VEGF-A expression and PTBE development (Table 1). Kalkanis and colleagues were the first to report the correlation between VEGF-A expression and PTBE development in meningiomas in $1996 .{ }^{42}$ VEGF-A mRNA was quantified using Northern blotting, and PTBE was evaluated with T2weighted and Gd-enhanced T1-weighted MRI. A marked increase of 3.4-times the level of VEGF-A mRNA was found in meningiomas with PTBE compared with those without $(\mathrm{p}<0.001)$. Subsequently, Goldman and colleagues investigated meningioma tissue samples from 37 patients. ${ }^{31}$ VEGF-A expression and PTBE were subjectively quantified on a 5-point scale with immunostaining and MRI, respectively. Similarly, a significantly positive correlation between VEGF-A staining intensity and MRI edema rating was demonstrated $(p=0.0001)$. In the study conducted by Ding and colleagues, PTBE was measured on MRI; VEGF-A protein and mRNA were quantified using Western blotting and reverse transcription polymerase chain reaction (RT-PCR), respectively. ${ }^{20}$ Within meningioma tissue, the expression of both VEGF-A protein and mRNA were congruent and had a significant correlation with edema index $(\mathrm{p}<0.01)$. Nassehi and colleagues in 2011 assessed only meningiomas affected by PTBE and quantified VEGF-A protein and mRNA level with an enzyme-linked immunosorbent assay-based method and PTBE with MRI. ${ }^{55}$ VEGF-A protein $(\mathrm{p}<0.05)$ and mRNA $(p<0.05)$ correlated positively with edema index. Multiple other studies have corroborated the relationship between VEGF-A and PTBE. ${ }^{10,56,59,60,65,68,75,78,97}$

\section{VEGF-A and Meningioma Vascularization}

A number of studies have demonstrated that VEGF-A expression is associated with meningioma vascularity, ${ }^{63-65,68,77}$ while others did not find such an association. ${ }^{19,44,62}$ One of the possible explanations for this inconsistency is the method used to measure vascularity.

Nassehi and colleagues were the only group to have used a stereology-based method to estimate the total capillary length to correlate with VEGF expression in meningiomas. ${ }^{55,56}$ The mean capillary length was $3614 \mathrm{~mm} /$ $\mathrm{mm}^{3}, 605 \mathrm{~mm} / \mathrm{mm}^{3}$, and $229 \mathrm{~mm} / \mathrm{mm}^{3}$ for angiomatous meningiomas ( $\mathrm{p}<0.0001 \mathrm{vs}$ control), nonangiomatous meningiomas ( $\mathrm{p}=0.014$ vs control), and control brain tissue, respectively. ${ }^{56}$ Consistently, VEGF-A protein and mRNA 
Peritumoral brain edema development

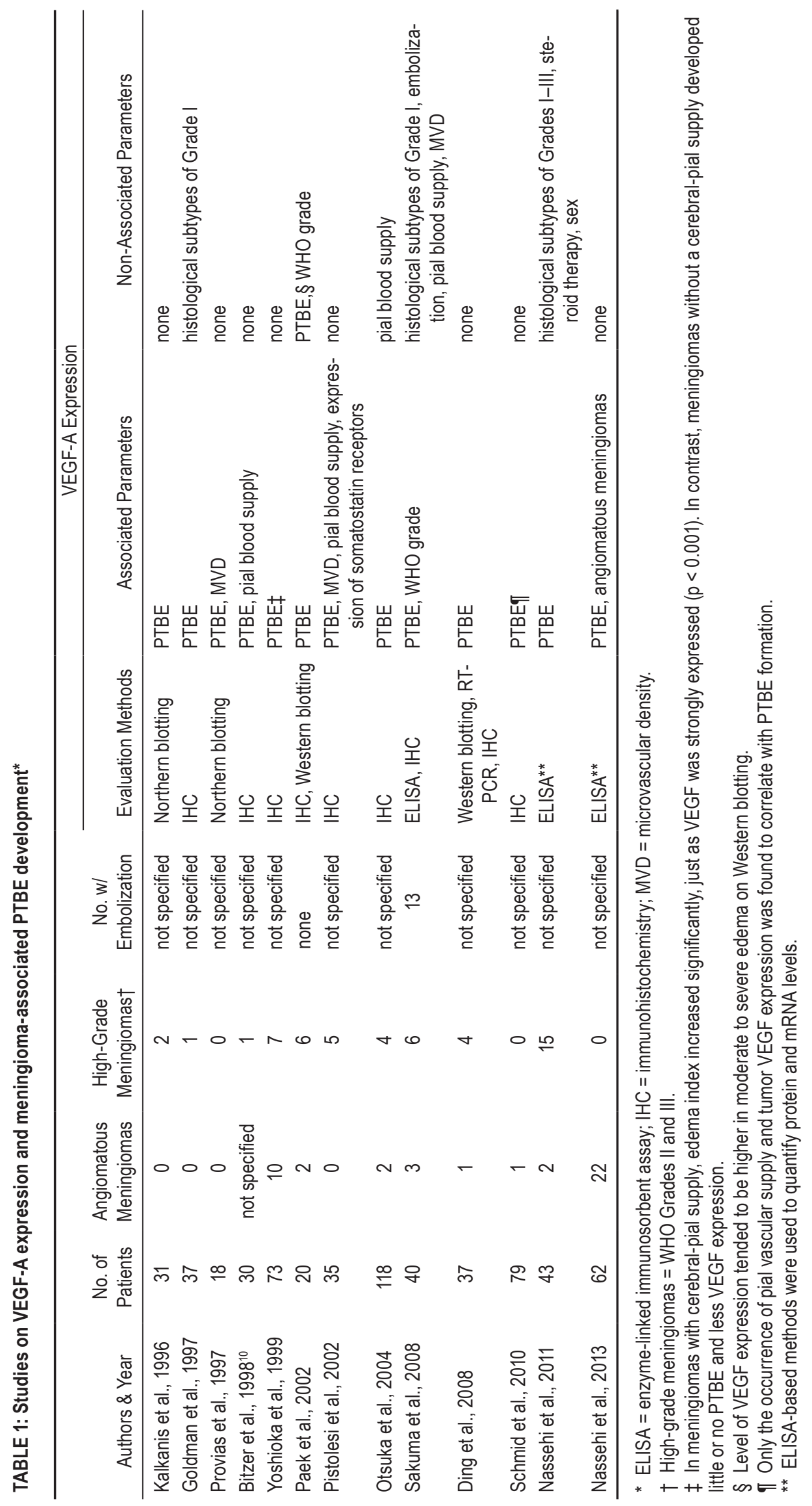




\section{J. Hou et al.}

levels were highest in angiomatous meningiomas and lowest in control tissue. ${ }^{55,56}$ Lamszus and colleagues demonstrated that VEGF-A found in protein extracts from human meningioma tissue induced capillary-like tube formation and migration of endothelial cells in vitro. ${ }^{44}$ These findings give reason to believe that VEGF-A is an important proangiogenic factor involved in angiogenesis in meningiomas.

\section{Source of VEGF-A}

Mounting evidence suggests that VEGF-A may be secreted by meningioma cells. Goldman and colleagues performed in situ hybridization of VEGF-A mRNA and localized these molecules in meningioma cells but not in peritumoral brain parenchyma, which indicates that PTBE may be a result of the ability of meningioma cells to produce VEGF-A locally, leading to increased tumor and peritumoral brain parenchyma vascularization and vascular permeability. ${ }^{31}$ Ding and colleagues compared peritumoral biopsied brain tissue $(n=37)$ with control brain tissue derived from temporal lobectomies performed for epilepsy. ${ }^{20}$ In the peritumoral brain, Western blot results were inconsistent with results for RT-PCR. The VEGF-A protein level was 5 times higher than controls, but mRNA level, similar to control brain tissue, was almost undetectable. With increasing distance from the tumor, decreasing concentration of VEGF-A protein level was observed. These data indicate that even though VEGF-A protein level in peritumoral brain tissue is high and is correlated with edema index,${ }^{20}$ brain parenchyma does not produce VEGF-A, and VEGF-A signaling molecules are produced by meningiomas, which then enter peritumoral brain tissue and stimulate edema formation.

\section{Tumor-Brain Barrier Disruption May Be an Essential Component of Edema Formation}

Meningiomas, in contrast to glioblastomas and metastases, are encapsulated and are separated from the underlying normal cerebral cortex by the arachnoid membrane and pia mater. As a part of the blood-CSF barrier, the arachnoid membrane is impermeable to fluids. ${ }^{39}$ Even though the pia mater is highly permeable to water and electrolytes, it is still far less pervious to macromolecules and proteins found in edema fluid..$^{29}$ Therefore, edemainducing proteins from meningiomas are not expected to easily penetrate into the peritumoral brain tissue. Therefore, the mechanism by which VEGF-A secreted by meningiomas reaches peritumoral brain parenchyma needs elucidation.

Peritumoral brain edema almost always occurs in glioblastomas, and its severity has been directly correlated with the level of VEGF-A. ${ }^{86}$ In contrast, it was reported that some meningiomas with high VEGF-A content did not develop PTBE..$^{31,42,68,97}$ This disparity may be explained by the differences in blood supply. A meningioma is an extraaxial tumor perfused by blood vessels from the dural meninges, the pia mater, or both,,${ }^{12,40}$ whereas glioblastoma is an intracerebral tumor perfused solely by pial blood vessels. Thus, it appears that in meningiomas,
VEGF-A is a potent edemagenic factor only under specific circumstances, and some degree of pial vascular supply to the tumor may be a critical factor in PTBE formation.

Several authors have demonstrated a correlation between VEGF-A expression and the presence of pial vascular supply in meningiomas. ${ }^{10,63,65}$ Inamura and colleagues were the first to show in meningiomas that the edema index was associated with the existence of cerebral-pial vessels. ${ }^{40}$ Subsequently, Bitzer and colleagues demonstrated on angiography that pial blush in meningiomas was strongly related to the incidence and degree of PTBE, and they proposed that cerebral-pial vessels may be a critical factor in edemagenesis. ${ }^{12}$ Similarly, Yoshioka and colleagues demonstrated that the edema index increased in proportion to the degree of VEGF expression in the presence of a pial blood supply, whereas no such association was observed in those with only dural blood supply. ${ }^{97}$ Lastly, Schmid and colleagues evaluated the vascular supply and arachnoid state intraoperatively, and revealed that only the presence of both pial vascular supply and VEGF-A expression found in tumors was clearly correlated with PTBE formation $(\mathrm{p}<0.002) .^{78}$

These data indicate that angiogenesis of pial-tumor vessels is an important step in the development of PTBE, and VEGF-A likely plays an important role in the development of pial vascular supply to the tumor. VEGF-A is produced by meningioma cells to bind to VEGFR-2 on the endothelial lining of pial vessels and promotes the proliferation of these vessels to penetrate through the arachnoid membrane to perfuse the tumor. Through disruption of the arachnoid membrane, VEGF-A and other edema-inducing macromolecules can enter normal peritumoral brain tissue to induce further angiogenesis and enhance vascular permeability, giving impetus to edemagenesis. Alternatively, VEGF-A may also reach normal brain through an intact cerebral-tumor microcirculation and directly cause edema formation without the need for a tumor with a benign nature to invade its well-encapsulated meningeal borders.

\section{Clinical Studies of VEGF Therapy}

A robust association does not inevitably impose a causal relationship. The definitive proof of efficacy will require studies involving VEGF inhibition and evaluation of the effect on PTBE. To this point, 3 case reports and 3 retrospective case series have used systemic VEGFdirected therapy, in particular bevacizumab, in meningiomas (Table 2). Bevacizumab is a humanized monoclonal antibody that inhibits VEGF activity by binding directly to all VEGF isoforms, to form a complex that becomes incapable of binding to receptor sites. ${ }^{26}$ It is currently approved by the US FDA for a variety of disorders, including glioblastoma.

In 2010, Puchner and colleagues presented the first case of bevacizumab use in meningioma. ${ }^{69}$ Salvage therapy with bevacizumab $(10 \mathrm{mg} / \mathrm{kg}$ body weight every 2 weeks) was initiated after the recurrence of an anaplastic meningioma following gross-total resection and postoperative adjuvant radiotherapy, and was well tolerated. Six weeks later, contrast-enhancing tumor regressed substan- 
Peritumoral brain edema development

TABLE 2: Literature on systemic anti-VEGF therapy against meningioma*

\begin{tabular}{|c|c|c|c|c|}
\hline Authors \& Year & Treatment (dose) & No. of Patients & Median PFS (mos) & PTBE \\
\hline Nayak et al., 2012 & $10 \mathrm{mg} / \mathrm{kg}$ every 2 wks & 15 (6 w/ Grade II, 9 w/ Grade III) & 6.5 & $40 \%$ regression; $60 \%$ stable \\
\hline Lou et al., 2012 & not specified & $\begin{array}{l}14 \text { (5 w/ Grade I, } 5 \text { w/ Grade II, } 3 \text { w/ } \\
\text { Grade III, } 1 \text { unknown) }\end{array}$ & 15.8 (for Grade II/III meningiomas) & not specified \\
\hline Nunes et al., 2013 & $5 \mathrm{mg} / \mathrm{kg}$ every 2 wks & 15 (grade unknown) & 20 & not specified \\
\hline
\end{tabular}

* All studies were retrospective.

tially, and FLAIR and T2-weighted MRI showed reduced edema. These changes were sustained for 6 months after the cessation of therapy. Wilson and Heth reported regression of a partially resected Grade I meningioma after paclitaxel and bevacizumab was used to treat breast cancer for 6 months and 1 year, respectively. ${ }^{95}$ Regression of the meningioma was maintained on follow-up MRI 1 year later. Goutagny and colleagues administered bevacizumab at a dose of $5 \mathrm{mg} / \mathrm{kg}$ body weight every 2 weeks for 15 months with the primary goal of treating a vestibular schwannoma in a patient with neurofibromatosis Type $2 .{ }^{32}$ Concomitantly, an unknown grade meningioma that measured $7.3 \mathrm{~cm}^{3}$ and grew $38 \%$ in volume over the preceding year decreased $22 \%$ in size throughout the course of the treatment.

In the first published case series, Nayak and colleagues administered bevacizumab with the primary aim of promoting regression of recurrent atypical and anaplastic menigniomas. ${ }^{57}$ The cohort consisted of 15 patients with multiple prior surgeries (median $=3$ ) and sessions of radiotherapy. The median number of recurrences was 4 per patient, and 7 patients received prior chemotherapy. A median of 9 doses of bevacizumab was given over 18 weeks. The median progression-free survival (PFS) was 6.5 months, and 6-month PFS was $44 \%$. Two patients showed minor shrinkage of the enhancing part of the tumor while the remaining cohort had stable disease. Six patients exhibited reduction in peritumoral T2 hyperintense areas on MRI consistent with decreased PTBE. Five patients improved clinically, 9 remained unchanged, and 1 patient's condition deteriorated.

In a similar study, Lou and colleagues treated 14 patients with bevacizumab as salvage therapy where all had recurrent/progressive meningioma. ${ }^{50}$ The primary end point was to assess 6-month PFS. Thirteen patients had previously undergone 1 or more resections, fractionated radiotherapy or stereotactic radiosurgery, chemotherapy, or biological targeted therapy, such as octreotide. Chemotherapy was used as an adjunct in $71 \%$ of patients. One patient with multifocal disease demonstrated partial response according to the criteria for malignant gliomas, as established by the Response Assessment in NeuroOncology ${ }^{94}$ While disease in 2 patients progressed, 11 patients exhibited stable disease. Median PFS and 6-month PFS were 12.2 months and $80 \%$, respectively, for patients with Grade I meningiomas, and 15.8 months and $87.5 \%$ for patients with Grade II/III meningiomas, respectively. The therapeutic effect on PTBE was not reported.

In a more recent report by Nune and colleagues, 15 patients neurofibromatosis Type 2 harboring a total of 48 meningiomas of unknown grade were given bevacizumab ( $5 \mathrm{mg} / \mathrm{kg}$ body weight) every 2 weeks. ${ }^{58}$ Although the effect on PTBE was not described, 29\% of meningiomas showed radiographic response with a 15-month median time to regression. The median PFS and 6-month PFS was 20 months and $93 \%$ on a per-patient basis, respectively.

To date, limited data have been published describing the antiedemagenic and antitumoral activity of VEGFdirected therapy for meningioma. However, several retrospective studies suggest that bevacizumab may be an efficacious treatment. Even though the patient population was heterogeneous and most patients in the aforementioned series were heavily pretreated, the outcome compared favorably to that achieved using other salvage systemic therapies. In the Phase II trials of hydroxyurea, temozolomide, irinotecan, imatinib, erlotinib/gefitinib, interferon- $\alpha$, tamoxifen, mifepristone, and octreotide for recurrent meningiomas, the median PFS ranged from 2 to 15 months. ${ }^{50} \mathrm{~A}$ decrease in PTBE on T2-weighted MRI was noted in $40 \%$ of patients, but all patients that had a decrease in PTBE demonstrated clinical improvement or remained stable. ${ }^{57}$ The lack of response in the remaining cohort emphasizes that VEGF-directed therapy is only beneficial under specific conditions, such as in the presence of a cerebral-pial blood supply and high VEGF-A to semaphorin-3A ratio. Further evaluation of this issue is warranted to determine which patients will respond best to therapy.

\section{Ongoing Trials}

Several clinical trials based on VEGF-A- or VEGFR-2-directed therapy for patients with recurrent or progressive meningiomas are ongoing. Phase II trials evaluating bevacizumab as monotherapy (clinicaltrials. gov identifier: NCT01125046) or in combination with everolimus, a mammalian target of rapamycin inhibitor (clinicaltrial.gov identifier: NCT00972335), are currently recruiting. Small molecules inhibiting VEGFR-2 and platelet-derived growth factor receptor signal transduction, such as sunitinib (clinicaltrial.gov identifier: NCT00589784) and vatalanib (clinicaltrial.gov identifier: NCT00348790), are also under Phase II investigation. Lastly, we await the results of a Phase II study on bevacizumab for reducing CNS side effects in patients who have undergone radiation therapy for intracranial meningiomas (clinicaltrial.gov identifier: NCT00492089).

\section{Conclusions}

Intracranial meningiomas are often complicated by 


\section{J. Hou et al.}

PTBE. To date, no reliable chemotherapeutic option exists for this complication. Naturally, the cause of edema generation is eliminated with tumor removal, but in most cases presurgical elimination or reduction in PTBE is desirable to reduce surgical morbidity. In addition, reduction of PTBE may decrease complications associated with radiation for meningiomas. Mounting evidence suggests PTBE may be the result of a cascade of events triggered by tumor VEGF-A production leading to increased microvascular permeability and neovascularization of tumoral and peritumoral brain tissue, causing extravasation of plasma proteins and ultimately PTBE. Understanding the VEGF-A and PTBE formation pathways may hold the key to a perioperative therapeutic approach to treating meningiomas with PTBE. Thus, a targeted inhibition of VEGF-A, VEGFR-2, or one of its substrates along the signal transduction pathway, and targeted activation of negative modulators of VEGF-A activity, may one day improve patient outcomes from PTBE-related complications of meningiomas.

\section{Disclosure}

Dr. Selman has direct stock ownership in Surgical Theater and Osteoplastics II.

Author contributions to the study and manuscript preparation include the following. Conception and design: all authors. Acquisition of data: Hou, Kshettry, Selman. Analysis and interpretation of data: all authors. Drafting the article: Hou, Kshettry. Critically revising the article: Bambakidis, Hou, Selman. Reviewed submitted version of manuscript: Bambakidis, Hou. Approved the final version of the manuscript on behalf of all authors: Bambakidis. Administrative/technical/material support: Hou .

\section{References}

1. Alaywan M, Sindou M: [Prognostic factors in the surgery for intracranial meningioma. Role of the tumoral size and arterial vascularization originating from the pia mater. Study of 150 cases.] Neurochirurgie 39:337-347, 1993 (Fr)

2. Alguacil-Garcia A, Pettigrew NM, Sima AA: Secretory meningioma. A distinct subtype of meningioma. Am J Surg Pathol 10:102-111, 1986

3. Andersen C, Astrup J, Gyldensted C: Quantitative MR analysis of glucocorticoid effects on peritumoral edema associated with intracranial meningiomas and metastases. J Comput Assist Tomogr 18:509-518, 1994

4. Andersen C, Jensen FT: Differences in blood-tumour-barrier leakage of human intracranial tumours: quantitative monitoring of vasogenic oedema and its response to glucocorticoid treatment. Acta Neurochir (Wien) 140:919-924, 1998

5. Arienta C, Caroli M, Crotti F, Villani R: Treatment of intracranial meningiomas in patients over 70 years old. Acta Neurochir (Wien) 107:47-55, 1990

6. Armitage PA, Schwindack C, Bastin ME, Whittle IR: Quantitative assessment of intracranial tumor response to dexamethasone using diffusion, perfusion and permeability magnetic resonance imaging. Magn Reson Imaging 25:303-310, 2007

7. Barresi V: Angiogenesis in meningiomas. Brain Tumor Pathol 28:99-106, 2011

8. Barresi V, Tuccari G: Increased ratio of vascular endothelial growth factor to semaphorin3A is a negative prognostic factor in human meningiomas. Neuropathology 30:537-546, 2010

9. Benzel EC, Gelder FB: Correlation between sex hormone binding and peritumoral edema in intracranial meningiomas. Neurosurgery 23:169-174, 1988
10. Bitzer M, Opitz H, Popp J, Morgalla M, Gruber A, Heiss E, et al: Angiogenesis and brain oedema in intracranial meningiomas: influence of vascular endothelial growth factor. Acta Neurochir (Wien) 140:333-340, 1998

11. Bitzer M, Topka H, Morgalla M, Friese S, Wöckel L, Voigt K: Tumor-related venous obstruction and development of peritumoral brain edema in meningiomas. Neurosurgery 42:730737, 1998

12. Bitzer M, Wöckel L, Luft AR, Wakhloo AK, Petersen D, Opitz H, et al: The importance of pial blood supply to the development of peritumoral brain edema in meningiomas. J Neurosurg 87:368-373, 1997

13. Bodsch W, Rommel T, Ophoff BG, Menzel J: Factors responsible for the retention of fluid in human tumor edema and the effect of dexamethasone. J Neurosurg 67:250-257, 1987

14. Bradac GB, Ferszt R, Bender A, Schörner W: Peritumoral edema in meningiomas. A radiological and histological study. Neuroradiology 28:304-312, 1986

15. Brandis A, Mirzai S, Tatagiba M, Walter GF, Samii M, Ostertag H: Immunohistochemical detection of female sex hormone receptors in meningiomas: correlation with clinical and histological features. Neurosurgery 33:212-218, 1993

16. Carmeliet P, Moons L, Luttun A, Vincenti V, Compernolle V, De Mol M, et al: Synergism between vascular endothelial growth factor and placental growth factor contributes to angiogenesis and plasma extravasation in pathological conditions. Nat Med 7:575-583, 2001

17. Claus EB, Bondy ML, Schildkraut JM, Wiemels JL, Wrensch M, Black PM: Epidemiology of intracranial meningioma. Neurosurgery 57:1088-1095, 2005

18. Colakoğlu N, Demirtaş E, Oktar N, Yüntem N, Islekel S, Ozdamar N: Secretory meningiomas. J Neurooncol 62:233241, 2003

19. Denizot Y, De Armas R, Caire F, Moreau JJ, Pommepuy I, Truffinet $\mathrm{V}$, et al: The quantitative analysis of bFGF and VEGF by ELISA in human meningiomas. Mediators Inflamm 2006: 36376, 2006

20. Ding YS, Wang HD, Tang K, Hu ZG, Jin W, Yan W: Expression of vascular endothelial growth factor in human meningiomas and peritumoral brain areas. Ann Clin Lab Sci 38: 344-351, 2008

21. Djindjian M, Caron JP, Athayde AA, Février MJ: Intracranial meningiomas in the elderly (over 70 years old). A retrospective study of 30 surgical cases. Acta Neurochir (Wien) 90: 121-123, 1988

22. Dolecek TA, Propp JM, Stroup NE, Kruchko C: CBTRUS statistical report: primary brain and central nervous system tumors diagnosed in the United States in 2005-2009. Neuro Oncol 14 Suppl 5:v1-v49, 2012

23. Donnell MS, Meyer GA, Donegan WL: Estrogen-receptor protein in intracranial meningiomas. J Neurosurg 50:499502, 1979

24. Dor Y, Porat R, Keshet E: Vascular endothelial growth factor and vascular adjustments to perturbations in oxygen homeostasis. Am J Physiol Cell Physiol 280:C1367-C1374, 2001

25. Ferrara N, Gerber HP, LeCouter J: The biology of VEGF and its receptors. Nat Med 9:669-676, 2003

26. Ferrara N, Hillan KJ, Gerber HP, Novotny W: Discovery and development of bevacizumab, an anti-VEGF antibody for treating cancer. Nat Rev Drug Discov 3:391-400, 2004

27. Galicich JH, French LA: Use of dexamethasone in the treatment of cerebral edema resulting from brain tumors and brain surgery. Am Pract Dig Treat 12:169-174, 1961

28. Galicich JH, French LA, Melby JC: Use of dexamethasone in treatment of cerebral edema associated with brain tumors. J Lancet 81:46-53, 1961

29. Gilbert JJ, Paulseth JE, Coates RK, Malott D: Cerebral edema associated with meningiomas. Neurosurgery 12:599-605, 1983 
30. Go KG, Wilmink JT, Molenaar WM: Peritumoral brain edema associated with meningiomas. Neurosurgery 23:175-179, 1988

31. Goldman CK, Bharara S, Palmer CA, Vitek J, Tsai JC, Weiss $\mathrm{HL}$, et al: Brain edema in meningiomas is associated with increased vascular endothelial growth factor expression. Neurosurgery 40:1269-1277, 1997

32. Goutagny S, Raymond E, Sterkers O, Colombani JM, Kalamarides M: Radiographic regression of cranial meningioma in a NF2 patient treated by bevacizumab. Ann Oncol 22: 990-991, 2011

33. Gu YT, Qin LJ, Qin X, Xu F: The molecular mechanism of dexamethasone-mediated effect on the blood-brain tumor barrier permeability in a rat brain tumor model. Neurosci Lett 452:114-118, 2009

34. Guttmann-Raviv N, Shraga-Heled N, Varshavsky A, Guimaraes-Sternberg C, Kessler O, Neufeld G: Semaphorin-3A and semaphorin- $3 \mathrm{~F}$ work together to repel endothelial cells and to inhibit their survival by induction of apoptosis. J Biol Chem 282:26294-26305, 2007

35. Hatam A, Yu ZY, Bergström M, Berggren BM, Greitz T: Effect of dexamethasone treatment on peritumoral brain edema: evaluation by computed tomography. J Comput Assist Tomogr 6:586-592, 1982

36. Higgins JN, Burnet NG, Schwindack CF, Waters A: Severe brain edema caused by a meningioma obstructing cerebral venous outflow and treated with venous sinus stenting. Case report. J Neurosurg 108:372-376, 2008

37. Hossmann KA: Morphological substrate of the blood-brain barrier in human brain tumors, in Klatzo I, Seitelberger F (eds): Brain Edema. New York: Springer-Verlag, 1967, pp 249-258

38. Ide M, Jimbo M, Kubo O, Yamamoto M, Takeyama E, Imanaga $\mathrm{H}$ : Peritumoral brain edema and cortical damage by meningioma. Acta Neurochir Suppl (Wien) 60:369-372, 1994

39. Ildan F, Tuna M, Göçer AP, Boyar B, Bağdatoğlu H, Sen O, et al: Correlation of the relationships of brain-tumor interfaces, magnetic resonance imaging, and angiographic findings to predict cleavage of meningiomas. J Neurosurg 91:384-390, 1999

40. Inamura T, Nishio S, Takeshita I, Fujiwara S, Fukui M: Peritumoral brain edema in meningiomas-influence of vascular supply on its development. Neurosurgery 31:179-185, 1992

41. Kalapurakal JA, Silverman CL, Akhtar N, Laske DW, Braitman LE, Boyko OB, et al: Intracranial meningiomas: factors that influence the development of cerebral edema after stereotactic radiosurgery and radiation therapy. Radiology 204:461-465, 1997

42. Kalkanis SN, Carroll RS, Zhang J, Zamani AA, Black PM: Correlation of vascular endothelial growth factor messenger RNA expression with peritumoral vasogenic cerebral edema in meningiomas. J Neurosurg 85:1095-1101, 1996

43. Ku DD, Zaleski JK, Liu S, Brock TA: Vascular endothelial growth factor induces EDRF-dependent relaxation in coronary arteries. Am J Physiol 265:H586-H592, 1993

44. Lamszus K, Lengler U, Schmidt NO, Stavrou D, Ergün S, Westphal M: Vascular endothelial growth factor, hepatocyte growth factor/scatter factor, basic fibroblast growth factor, and placenta growth factor in human meningiomas and their relation to angiogenesis and malignancy. Neurosurgery 46:938948,2000

45. Lee KJ, Joo WI, Rha HK, Park HK, Chough JK, Hong YK, et al: Peritumoral brain edema in meningiomas: correlations between magnetic resonance imaging, angiography, and pathology. Surg Neurol 69:350-355, 2008

46. Leung DW, Cachianes G, Kuang WJ, Goeddel DV, Ferrara N: Vascular endothelial growth factor is a secreted angiogenic mitogen. Science 246:1306-1309, 1989

47. Li X, Claesson-Welsh L, Shibuya M: VEGF receptor signal transduction. Methods Enzymol 443:261-284, 2008
48. Lieu AS, Howng SL: Intracranial meningiomas and epilepsy: incidence, prognosis and influencing factors. Epilepsy Res 38:45-52, 2000

49. Lobato RD, Alday R, Gómez PA, Rivas JJ, Domínguez J, Cabrera A, et al: Brain oedema in patients with intracranial meningioma. Correlation between clinical, radiological, and histological factors and the presence and intensity of oedema. Acta Neurochir (Wien) 138:485-494, 1996

50. Lou E, Sumrall AL, Turner S, Peters KB, Desjardins A, Vredenburgh JJ, et al: Bevacizumab therapy for adults with recurrent/progressive meningioma: a retrospective series. J Neurooncol 109:63-70, 2012

51. Luo Y, Raible D, Raper JA: Collapsin: a protein in brain that induces the collapse and paralysis of neuronal growth cones. Cell 75:217-227, 1993

52. Maiuri F, Gangemi M, Cirillo S, Delehaye L, Gallicchio B, Carandente M, et al: Cerebral edema associated with meningiomas. Surg Neurol 27:64-68, 1987

53. Marosi C, Hassler M, Roessler K, Reni M, Sant M, Mazza E, et al: Meningioma. Crit Rev Oncol Hematol 67:153-171, 2008

54. Miao HQ, Soker S, Feiner L, Alonso JL, Raper JA, Klagsbrun M: Neuropilin-1 mediates collapsin-1/semaphorin III inhibition of endothelial cell motility: functional competition of collapsin-1 and vascular endothelial growth factor-165. J Cell Biol 146:233-242, 1999

55. Nassehi D, Dyrbye H, Andresen M, Thomsen C, Juhler M, Laursen H, et al: Vascular endothelial growth factor A protein level and gene expression in intracranial meningiomas with brain edema. APMIS 119:831-843, 2011

56. Nassehi D, Sørensen LP, Dyrbye H, Thomsen C, Juhler M, Laursen $\mathrm{H}$, et al: Peritumoral brain edema in angiomatous supratentorial meningiomas: an investigation of the vascular endothelial growth factor A pathway. APMIS [epub ahead of print], 2013

57. Nayak L, Iwamoto FM, Rudnick JD, Norden AD, Lee EQ, Drappatz J, et al: Atypical and anaplastic meningiomas treated with bevacizumab. J Neurooncol 109:187-193, 2012

58. Nunes FP, Merker VL, Jennings D, Caruso PA, di Tomaso E, Muzikansky A, et al: Bevacizumab treatment for meningiomas in NF2: a retrospective analysis of 15 patients. PLoS ONE 8:e59941, 2013

59. Otsuka S, Tamiya T, Ono Y, Michiue H, Kurozumi K, Daido $\mathrm{S}$, et al: The relationship between peritumoral brain edema and the expression of vascular endothelial growth factor and its receptors in intracranial meningiomas. J Neurooncol 70: 349-357, 2004

60. Paek SH, Kim CY, Kim YY, Park IA, Kim MS, Kim DG, et al: Correlation of clinical and biological parameters with peritumoral edema in meningioma. J Neurooncol 60:235-245, 2002

61. Philippon J, Foncin JF, Grob R, Srour A, Poisson M, Pertuiset BF: Cerebral edema associated with meningiomas: possible role of a secretory-excretory phenomenon. Neurosurgery 14: 295-301, 1984

62. Pietsch T, Valter MM, Wolf HK, von Deimling A, Huang HJ, Cavenee WK, et al: Expression and distribution of vascular endothelial growth factor protein in human brain tumors. Acta Neuropathol 93:109-117, 1997

63. Pistolesi S, Boldrini L, Gisfredi S, De Ieso K, Camacci T, Caniglia M, et al: Angiogenesis in intracranial meningiomas: immunohistochemical and molecular study. Neuropathol Appl Neurobiol 30:118-125, 2004

64. Pistolesi S, Fontanini G, Boldrini L, Camacci T, De Ieso K, Lupi G, et al: The role of somatostatin in vasogenic meningioma associated brain edema. Tumori 89:136-140, 2003

65. Pistolesi S, Fontanini G, Camacci T, De Ieso K, Boldrini L, Lupi G, et al: Meningioma-associated brain oedema: the role of angiogenic factors and pial blood supply. J Neurooncol 60: 159-164, 2002 


\section{J. Hou et al.}

66. Preston-Martin S: Epidemiology of primary CNS neoplasms. Neurol Clin 14:273-290, 1996

67. Probst-Cousin S, Villagran-Lillo R, Lahl R, Bergmann M, Schmid KW, Gullotta F: Secretory meningioma: clinical, histologic, and immunohistochemical findings in 31 cases. Cancer 79:2003-2015, 1997

68. Provias J, Claffey K, delAguila L, Lau N, Feldkamp MGA, Guha A: Meningiomas: role of vascular endothelial growth factor/vascular permeability factor in angiogenesis and peritumoral edema. Neurosurgery 40:1016-1026, 1997

69. Puchner MJ, Hans VH, Harati A, Lohmann F, Glas M, Herrlinger U: Bevacizumab-induced regression of anaplastic meningioma. Ann Oncol 21:2445-2446, 2010

70. Regelsberger J, Hagel C, Emami P, Ries T, Heese O, Westphal $\mathrm{M}$ : Secretory meningiomas: a benign subgroup causing lifethreatening complications. Neuro Oncol 11:819-824, 2009

71. Riemenschneider MJ, Perry A, Reifenberger G: Histological classification and molecular genetics of meningiomas. Lancet Neurol 5:1045-1054, 2006

72. Roberts WG, Palade GE: Increased microvascular permeability and endothelial fenestration induced by vascular endothelial growth factor. J Cell Sci 108:2369-2379, 1995

73. Rohringer M, Sutherland GR, Louw DF, Sima AA: Incidence and clinicopathological features of meningioma. J Neurosurg 71:665-672, 1989

74. Ryan R, Booth S, Price S: Corticosteroid-use in primary and secondary brain tumour patients: a review. J Neurooncol 106: 449-459, 2012

75. Sakuma T, Nakagawa T, Ido K, Takeuchi H, Sato K, Kubota $\mathrm{T}$ : Expression of vascular endothelial growth factor-A and mRNA stability factor HuR in human meningiomas. J Neurooncol 88: $143-155,2008$

76. Salpietro FM, Alafaci C, Lucerna S, Iacopino DG, Todaro C, Tomasello F: Peritumoral edema in meningiomas: microsurgical observations of different brain tumor interfaces related to computed tomography. Neurosurgery 35:638-642, 1994

77. Samoto K, Ikezaki K, Ono M, Shono T, Kohno K, Kuwano $\mathrm{M}$, et al: Expression of vascular endothelial growth factor and its possible relation with neovascularization in human brain tumors. Cancer Res 55:1189-1193, 1995

78. Schmid S, Aboul-Enein F, Pfisterer W, Birkner T, Stadek C, Knosp E: Vascular endothelial growth factor: the major factor for tumor neovascularization and edema formation in meningioma patients. Neurosurgery 67:1703-1708, 2010

79. Senger DR, Galli SJ, Dvorak AM, Perruzzi CA, Harvey VS, Dvorak HF: Tumor cells secrete a vascular permeability factor that promotes accumulation of ascites fluid. Science 219: 983-985, 1983

80. Sindou MP, Alaywan M: Most intracranial meningiomas are not cleavable tumors: anatomic-surgical evidence and angiographic predictibility. Neurosurgery 42:476-480, 1998

81. Sinha S, Bastin ME, Wardlaw JM, Armitage PA, Whittle IR: Effects of dexamethasone on peritumoural oedematous brain: a DT-MRI study. J Neurol Neurosurg Psychiatry 75:16321635,2004

82. Skjoeth J, Bjerre PK: Effect of glucocorticoids on ICP in patients with a cerebral tumour. Acta Neurol Scand 96:167170,1997

83. Smith HP, Challa VR, Moody DM, Kelly DL Jr: Biological features of meningiomas that determine the production of cerebral edema. Neurosurgery 8:428-433, 1981

84. Soker S, Takashima S, Miao HQ, Neufeld G, Klagsbrun M: Neuropilin-1 is expressed by endothelial and tumor cells as an isoform-specific receptor for vascular endothelial growth factor. Cell 92:735-745, 1998
85. Staton CA, Kumar I, Reed MW, Brown NJ: Neuropilins in physiological and pathological angiogenesis. J Pathol 212: 237-248, 2007

86. Strugar JG, Criscuolo GR, Rothbart D, Harrington WN: Vascular endothelial growth/permeability factor expression in human glioma specimens: correlation with vasogenic brain edema and tumor-associated cysts. J Neurosurg 83:682-689, 1995

87. Tamiya T, Ono Y, Matsumoto K, Ohmoto T: Peritumoral brain edema in intracranial meningiomas: effects of radiological and histological factors. Neurosurgery 49:1046-1052, 2001

88. Tanaka M, Imhof HG, Schucknecht B, Kollias S, Yonekawa Y, Valavanis A: Correlation between the efferent venous drainage of the tumor and peritumoral edema in intracranial meningiomas: superselective angiographic analysis of 25 cases. J Neurosurg 104:382-388, 2006

89. Tirakotai W, Mennel HD, Celik I, Hellwig D, Bertalanffy H, Riegel T: Secretory meningioma: immunohistochemical findings and evaluation of mast cell infiltration. Neurosurg Rev 29:41-48, 2006

90. Trittmacher S, Traupe H, Schmid A: Pre- and postoperative changes in brain tissue surrounding a meningioma. Neurosurgery 22:882-885, 1988

91. Vaz R, Borges N, Cruz C, Azevedo I: Cerebral edema associated with meningiomas: the role of peritumoral brain tissue. $\mathbf{J}$ Neurooncol 36:285-291, 1998

92. Vignes JR, Sesay M, Rezajooi K, Gimbert E, Liguoro D: Peritumoral edema and prognosis in intracranial meningioma surgery. J Clin Neurosci 15:764-768, 2008

93. Wang DJ, Xie Q, Gong Y, Wang Y, Cheng HX, Mao Y, et al: Secretory meningiomas: clinical, radiological and pathological findings in 70 consecutive cases at one institution. Int $\mathbf{J}$ Clin Exp Pathol 6:358-374, 2013

94. Wen PY, Macdonald DR, Reardon DA, Cloughesy TF, Sorensen AG, Galanis E, et al: Updated response assessment criteria for high-grade gliomas: response assessment in neurooncology working group. J Clin Oncol 28:1963-1972, 2010

95. Wilson TJ, Heth JA: Regression of a meningioma during paclitaxel and bevacizumab therapy for breast cancer. J Clin Neurosci 19:468-469, 2012

96. Wrensch M, Minn Y, Chew T, Bondy M, Berger MS: Epidemiology of primary brain tumors: current concepts and review of the literature. Neuro Oncol 4:278-299, 2002

97. Yoshioka H, Hama S, Taniguchi E, Sugiyama K, Arita K, Kurisu K: Peritumoral brain edema associated with meningioma: influence of vascular endothelial grow th factor expression and vascular blood supply. Cancer 85:936-944, 1999

98. Yu ZY, Wrange O, Boëthius J, Hatam A, Granholm L, Gustafsson JA: A study of glucocorticoid receptors in intracranial tumors. J Neurosurg 55:757-760, 1981

99. Zhou J, Cidlowski JA: The human glucocorticoid receptor: one gene, multiple proteins and diverse responses. Steroids 70: 407-417, 2005

Manuscript submitted July 18, 2013.

Accepted August 16, 2013.

Please include this information when citing this paper: DOI: 10.3171/2013.8.FOCUS13301.

Address correspondence to: Nicholas C. Bambakidis, M.D., Department of Neurological Surgery, University Hospitals Case Medical Center, 11100 Euclid Ave., Cleveland, OH 44106. email: nicholas.bambakidis2@uhhospitals.org. 